\title{
Increasing Celery Resistance to Pathogens during Storage and Reducing High-risk Psoralen Concentration by Treatment with $\mathbf{G A}_{3}$
}

\author{
U. Afek, N. Aharoni, and S. Carmeli ${ }^{1}$ \\ Department of Postharvest Science and Fresh Produce, Agricultural Research Organization, The \\ Volcani Center, Bet Dagan 50250, Israel
}

Additional index words. marmesin, Apium graveolens, gibbereline, decay

\begin{abstract}
Since psoralens have a very weak antifungal activity in vitro, we propose that (+)marmesin, the precursor of psoralens in celery (Apium graveolens $\mathbf{L}$.) is associated with celery resistance to pathogens. (+)Marmesin has at least 100 times greater antifungal activity in vitro than psoralens. After 1 month of storage at $2 \mathrm{C}$, the concentration of total psoralens increased from 8 to $67 \mu \mathrm{g} \cdot \mathrm{g}^{-1}$ fresh weight, (+)marmesin decreased from $27 \mathrm{to} 4 \mu \mathrm{g} \cdot \mathrm{g}^{-1}$ fresh weight, and the incidence of decay increased from $0 \%$ to $34 \%$. However, when celery was treated with GA̧before 1 month of storage at $2 \mathrm{C}$, decay increased to only $7 \%$, the concentration of psoralens increased to $31 \mu \mathrm{g}^{-1} \mathrm{~g}^{-1}$ fresh weight and the concentration of (+)marmesin decreased to $13 \mu \mathrm{g} \cdot \mathrm{g}^{-1}$ fresh weight It seems that $\mathbf{G A}_{3}$ retarded celery decay during storage by slowing down the conversion of $(+)$ marmesin to psoralens, thereby increasing the resistance to pathogens during storage.
\end{abstract}

Linear furanocoumarins (psoralens) are believed to be phytoalexins associated with celery resistance to pathogens (Beier and Oertli, 1983; Beieret al., 1983a; Chaudhary et al., 1985). Beier and Oertli (1983) demonstrated that the phytoalexin response was also initiated by general elicitors including copper sulfate, UV light, and low temperatures. Mechanical damage occurring during harvesting and storage has also been shown to increase furanocoumarin concentration from about 2 to $95 \mu \mathrm{g} \cdot \mathrm{g}^{-1}$ fresh weight (Chaudhary et al., 1985).

Psoralens produced by celery have several biological effects, the most important of which are photosensitized reactions with nucleic acids. Photosensitized reactions of DNA with furanocoumarins cause lethal, mutagenic, and clastogenic effects in a variety of cellular systems (Ashwood-Smith et al., 1980, 1982; Scott et al., 1976). Photocarcinogenesis occurs in animals exposed to the combined effects of psoralens and near-UV light; it probably also occurs in humans. Effective wavelengths for these phototoxic reactions are 320-380 $\mathrm{nm}$ (Chaudhary et al., 1985; Igali et al., 1970; Miller et al., 1984). Psoralen-UVA light (PUVA) photochemotherapy for psoriasis is recognized by the World Health Organization to be causally related to human skin cancer (IARC, 1983).

Phytophotodermatitis (a skin disorder caused by psoralens) has been reported $\mathrm{m}$ field workers after contact with celery (Austad and Kalvi, 1983; Birmingham et al., 1961; Finkelstein et al., 1994). Other studies (Berkley et al., 1986; Seligman et al., 1987) have found that phytophotodermatitis occurs in grocery workers. Psoralens also exist in other plants, such as parsnips, parsley, figs, and citrus (Pathak et al., 1961).

Gibberellins (GA), are naturally occurring phytohormones that exist in relatively high content in juvenile plant tissues compared with older tissues (Nooden, 1988). GA activity has been found to decline before or during leaf senescence (Aharoni and Richmond, 1978; Chin and Beevers, 1970; Nooden, 1988). This trend is accompanied by decreased resistance of the plant tissue to micro-

Received for publication 6 Oct. 1994. Accepted for publication 10 Feb. 1995. Contribution from the Agricultural Research Organization, The Volcani Center, Bet Dagan, Israel. No. 1320-E, 1994 series. The cost of publishing this paper was defrayed in part by the payment of page charges. Under postal regulations, this paper therefore must be hereby marked advertisement solely to indicate this fact. ${ }^{1}$ School of Chemistry, Tel Aviv Univ., Ramat Aviv, Tel Aviv 69978, Israel. bial attack. Exogenously supplied gibberellic acid $\left(\mathrm{GA}_{3}\right)$ delayed senescence and reduced rot incidence in a wide range of plant organs, including flowers (Shaul et al., 1992), fruit, and vegetative tissues (Nooden, 1988). Applied $\mathrm{GA}_{3}$ delayed chlorophyll loss and decay in harvested lettuce (Aharoni et al., 1975) and celery (Barkai-Golan and Aharoni, 1981). GA also prevents decay in fresh herbs of the Umbelliferae family such as parsley, dill, coriander, and chervil (N. Aharoni, unpublished data). The effect of exogenous $\mathrm{GA}_{3}$ was most pronounced when either leaf age or stress conditions resulted in the depletion of the endogenous content of the phytohormone (Aharoni and Richmond, 1978; Chin and Beevers, 1970; Nooden, 1988). However, the mechanism by which $\mathrm{GA}_{3}$ increases plant resistance remains unclear.

$(+)$ Marmesin has been reported as the precursor of linear furanocoumarins in several species belonging to the Apiaceae, Rutaceae, Moraceae, and Leguminoseae (Brown, 1978; Floss, 1972; Floss and Mothes, 1966; Floss and Paikert, 1969; Hamerski and Matern, 1988; Matern et al., 1988; Steck et al., 1969). The main objectives of this work are to determine whether (+)marmesin, rather than psoralens, may play the major role in celery resistance to pathogens during storage, and whether $\mathrm{GA}_{3}$ increases celery resistance to pathogens by slowing down the conversion of (+)marmesin to psoralens and maintaining high levels of $(+)$ marmesin and low levels of psoralens in celery.

\section{Materials and Methods}

Fungal, plant material and $\mathrm{GA}_{3}$ treatment. The fungi Botrytis cinerea Pers., Alternaria alternata (Fr.) Keissler, and Sclerotinia sclerotiorum (Lib). Dby were used in the experiments. These fungi, which are major pathogens causing rot diseases to celery, were isolated from naturally infected 'Tender Crisp' celery from Kibbutz Alumim, the Negev Desert, Israel, in January 1991. 'Early Bell' celery petioles were used for the experiments and inoculations. Percentages of celery decay and concentrations of $(+)$ marmesin and total psoralens (psoralen, bergapten, xanthotoxin, and isopimpinellin) were measured weekly during 1 month of storage at $2 \mathrm{C}$. $\mathrm{GA}_{3}$ was applied by dipping celery heads (trimmed as per standard marketing practices) for $10 \mathrm{sec}$ into water containing $20 \mathrm{mg} \cdot \mathrm{liter}^{-1}$ of $\mathrm{GA}_{3}$ before storage.

(+)Marmesin for use as a standard was obtained from celery 
petioles inoculated with $B$. cinerea. Four to five 3-mm-long incisions, $0.2-0.5 \mathrm{~mm}$ deep, were cut with a sterile scalpel into each celery petiole $(5-30 \mathrm{~cm}$ long and $2-3 \mathrm{~cm}$ thick). A 3-mmdiameter disk, cut from an actively growing potato-dextrose agar (PDA) culture of B. cinerea, was placed over each incision, fungal side downward, and the inoculated petioles were incubated for 4 days in a dark chamber at $98 \%$ relative humidity and $24 \mathrm{C}$.

Extraction, purification, isolation, identification and quantification of psoralens and (+)marmesin in celery. Extraction was done 4 days after inoculation with $B$. cinerea. Slices of inoculated celery petioles with necrotic lesions cut from the margins of the wounds (220 g fresh weight) were extracted with distilled water, at $10 \mathrm{ml} \cdot \mathrm{g}^{-1}$ fresh weight tissue, for $2 \mathrm{~h}$ at $40 \mathrm{C}$. Following partition with ethyl acetate (EtOAc) and concentration by evaporating the solvent at 40C in a Rotovac evaporator, purification, isolation, and identification of psoralen, bergapten, xanthotoxin, and isopimpinellin were performed using known techniques (Beier, 1985; Beier et al., 1983b; Dercks et al., 1990; Trumble et al., 1990). The crude material (340 mg) was loaded onto a vacuum column (Merck Silica H, 5 g, packed into a 2-cm-i.d., 30-cm-tall, sintered glass funnel, evacuated by a water aspirator) and eluted in petroleum ether with an EtOAc increasing step gradient to yield 12 fractions ( $50 \mathrm{ml}$ each). The fractions were assayed for antifungal activity against $B$. cinerea. Fraction 7 , eluted from the column with $40 \%$ EtOac in petroleum ether, was the most active against this fungus.

Preparative high-performance liquid chromatography (HPLC) separations were performed with an Applied Biosystems instrument equipped with two model 150 pumps and an 893 programmable detector. Fraction 7 (27 mg) was purified on a preparative HPLC column (Altech Econsil $\mathrm{C}_{18}$, reverse phase, $10 \mu \mathrm{m}, 250 \times 22$ $\mathrm{mm})$ using $70 \mathrm{MeOH}$ : 30 water as the eluant $\left(5 \mathrm{ml} \cdot \mathrm{min}^{-1}\right)$ with UV detection at $254 \mathrm{~nm}$. The chromatogram yielded eight components, with relative retention times $\left(\mathrm{t}_{\mathrm{R}} \mathrm{s}\right)$ of $7.5,8.5,9.3,11.5,13$, $14,14.8$, and $18.1 \mathrm{~min}$. The last component $\left(\mathrm{t}_{\mathrm{R}} 18.1 \mathrm{~min}, 3.1 \mathrm{mg}\right)$ was found to be the main active compound of the mixture. Mass spectra were recorded on a Finnigan MAT ITD-800 GC-MS instrument equipped with a DB- 1 capillary, minibore column (carrier gas: helium, $1 \mathrm{ml} / \mathrm{min}$ ) coupled to the NIST mass-spectra library and were identified by comparison with the NIST database as (+)marmesin. GC-MS data $\left(\mathrm{t}_{\mathrm{R}} 21.13 \mathrm{~min}, 70 \mathrm{eV}\right) \mathrm{m} / \mathrm{z} 246(\mathrm{M}+$, $100 \%), 213,187,160,131,102,77$, and 59. NMR spectra were recorded on a Bruker WM- 360 operating at $360.132 \mathrm{MHz}$ for ${ }^{1} \mathrm{H}$. NMR data, ${ }^{1} \mathrm{HNMR}$ data $\left(\mathrm{CDCl}_{3}: \mathrm{CD}_{3} \mathrm{OD} 1: 20\right)$, and (multiplicity, $\mathrm{J}$ in $\mathrm{Hz}$, assignment): $6.22(\mathrm{~d}, \mathrm{~J}=9.3 \mathrm{~Hz}, \mathrm{H}-3), 7.60(\mathrm{~d}, \mathrm{~J}=9.3 \mathrm{~Hz}$, H-4), 7.22 (s, H-5), 6.75 (s, H-8), 3.20 (old, J = 8.6 and 15.7 Hz, H9), $3.22(\mathrm{dd}, \mathrm{J}=9.1$ and $15.7 \mathrm{~Hz}, \mathrm{H}-9), 4.74(\mathrm{dd}, \mathrm{J}=8.6$ and $9.1 \mathrm{~Hz}$, $\mathrm{H}-10), 1.24$ (s, $\left.\mathrm{H}_{3}-12\right)$, and 1.37 (s, $\left.\mathrm{H}_{3}-12\right)$.

(+)Marmesin and psoralens were also identified by thin-layer chromatography (TLC) (0.5 mm, Art. 7730, Kieselgel 60 GF254, E. Merck, Darmstadt, Germany). Ascending TLC was developed in a mixture of 1 toluene: $1 \mathrm{EtOAc}(\mathrm{v} / \mathrm{v})$, dried and inspected under UV light (365 rim), and gave fluorescent spots: $R_{f}=3$ for (+)marmesin and $\mathrm{R}_{\mathrm{f}}=7$ for psoralens. Quantifications of (+)marmesin and psoralens in celery during 1 month of storage at $2 \mathrm{C}$ were obtained by means of analytical HPLC carried out with an L-6200 pump, an L-4200 UV-VIS detector, and a D-200 ChromatIntegrator (Merk-Hitachi, Tokyo). A Machery-Nagel (Duren, Germany) Nucleosil silica column $(250 \times 4 \mathrm{~mm})$ containing $\mathrm{C}_{18}$ reverse-phase packing of $5-\mu \mathrm{m}$ particle size, with a $15 \times 4$-mm guard column filled with the same packing material was used. All standards and samples were dissolved in methanol. For standards we used (+)marmesin from our own source, after purification and identification as described above; psoralen, bergapten, and xanthotoxin were purchased from Sigma, and isopimpinellin was provided by R.C. Beier, the Veterinary Toxicology and Entomology Research Laboratory, U.S. Dept. of Agriculture-Agricultural Research Service, College Station, Texas. These standards were eluted isocritically with 45 methanol :55 water (mixed by HPLC pump) at a flow rate of $0.4 \mathrm{ml} \cdot \mathrm{min}^{-1}$. Peaks were monitored and quantified at $254 \mathrm{~nm}$. Relative $\mathrm{t}_{\mathrm{R}} \mathrm{s}$ were as follows: (+)marmesin, 6. 15; psoralen, 6.40; bergapten, 6.85; xanthotoxin, 6.66; isopimpinellin, 7.09 .

UVA measurements. UVA measurements in the area (The Northern Negev, Israel; $31^{\circ}$ and $20 \mathrm{~min} \mathrm{~N}$ lat.) were recorded using an optronic 742 spectroradiometer, which measured the irradianic at $1-\mathrm{nm}$ intervals. Total UVA $(320-380 \mathrm{~nm})$ was obtained by integrating the spectroradiometric reading over this range. The amount of UVA present at solar noon (June) inside the greenhouse was $4.8 \mathrm{~mW} \cdot \mathrm{cm}^{-2}$ (there was no difference between measurements carried out inside and outside the greenhouse). This is about 50\% more irradiation than Bruyneel-Rapp et al. (1988) measured in normal sunlight in June at $34^{\circ}$ and $45 \mathrm{~min} \mathrm{~N}$ lat. at solar noon.

Bioassays. Bioassays were carried out for psoralens and (+)marmesin, exposed and not exposed to UVA. $\mathrm{EC}_{50}$ values for $B$. cinerea, A. alternata, and S. sclerotiorum were determined by adding increasing concentrations of marmesin and psoralens to cooled molten potato-dextrose agar (PDA) immediately before pouring into petri plates. Plates were then incubated in darkness or under sunlight (in June) in a greenhouse at $24 \mathrm{C}$. The $\mathrm{EC}_{50}$ values for colony area growth in these plates were calculated from the regression lines obtained by plotting the percent inhibition of growth against the log concentration of the compounds.

Statistical analysis. All experiments were conducted in a completely randomized design with five replicates for each treatment. Data were analyzed by an ANOVA procedure using the SAS (Cary, N. C.) package. Experiments were conducted three times.

\section{Results and Discussion}

Our findings indicate that (+)marmesin, and not psoralens, is the major compound involved in celery resistance to pathogens. In vitro, $\mathrm{EC}_{50}$ values of (+)marmesin has at least 100 times greater antifungal activity than psoralens (Table 1). There was no effect of the light on antifungal activity of psoralens and (+)marmesin. The in vivo concentration of psoralens in celery is $8 \mu \mathrm{g} \cdot \mathrm{g}^{-1}$ fresh weight,

Table 1. Effective concentrations of psoralens and their precursor, (+)marmesin, needed for obtaining $50 \%$ growth inhibition $\left(\mathrm{EC}_{50}\right)$ of three pathogenic fungi of celery.

\begin{tabular}{lccccc}
\hline \hline & \multicolumn{4}{c}{$\mathrm{E} \mathrm{C}_{50}$ values $\left(\mu \mathrm{g} \cdot \mathrm{ml}^{-1}\right)$} \\
\cline { 2 - 6 } Pathogens & Psoralen & Bergapten & Xanthotoxin & Isopimpinellin & $(+)$ Marmesin \\
\hline Botrytis cinerea & 4150 & 4740 & 4550 & 5270 & 28 \\
Alternaria alternata & 5040 & 5890 & 5540 & 6330 & 43 \\
Sclerotinia sclerotiorum & 3620 & 3970 & 3310 & 4050 & 19 \\
\hline
\end{tabular}


and this is only $0.27 \%$ of the concentration required for growth inhibition of celery pathogens in vitro. On the other hand, $\mathrm{The}_{50}$ values of $(+)$ marmesin $\left(19,28\right.$, and $\left.43 \mu \mathrm{g} \cdot \mathrm{ml}^{-1}\right)$ is close to the natural amount occurring in vivo (27 $\mu \mathrm{g} \cdot \mathrm{g}^{-1}$ fresh weight). Additionally, increased susceptibility of stored celery to pathogens was accompanied by a decrease in (+)marmesin concentration and a corresponding increase in total psoralen concentration (Fig. 1). An increase in celery decay has been found to be negatively correlated with $(+)$ marmesin concentration $\left(r^{2}=0.927: \mathrm{y}=33.2-0.28 \mathrm{x}\right)$ and positively correlated with psoralen concentration $\left(r^{2}=0.956\right.$; $\mathrm{y}=$ $8.3+0.47 \mathrm{x})$. After 1 month of storage at $2 \mathrm{C}$, the concentration of total psoralens (psoralen, bergapten, xanthotoxin, and isopimpinellin) increased from 8 to $67 \mu \mathrm{g} \cdot \mathrm{g}^{-1}$ fresh weight, whereas the concentration of (+)marmesin under the same storage conditions decreased from 27 to $4 \mu \mathrm{g} \cdot \mathrm{g}^{-1}$ fresh weight. Incidence of decay after 1 month of storage at $2 \mathrm{C}$ was $34 \%$ (Fig. 1). All of these findings indicate that psoralens cannot play a major role in the defense mechanism of celery against these pathogens and that
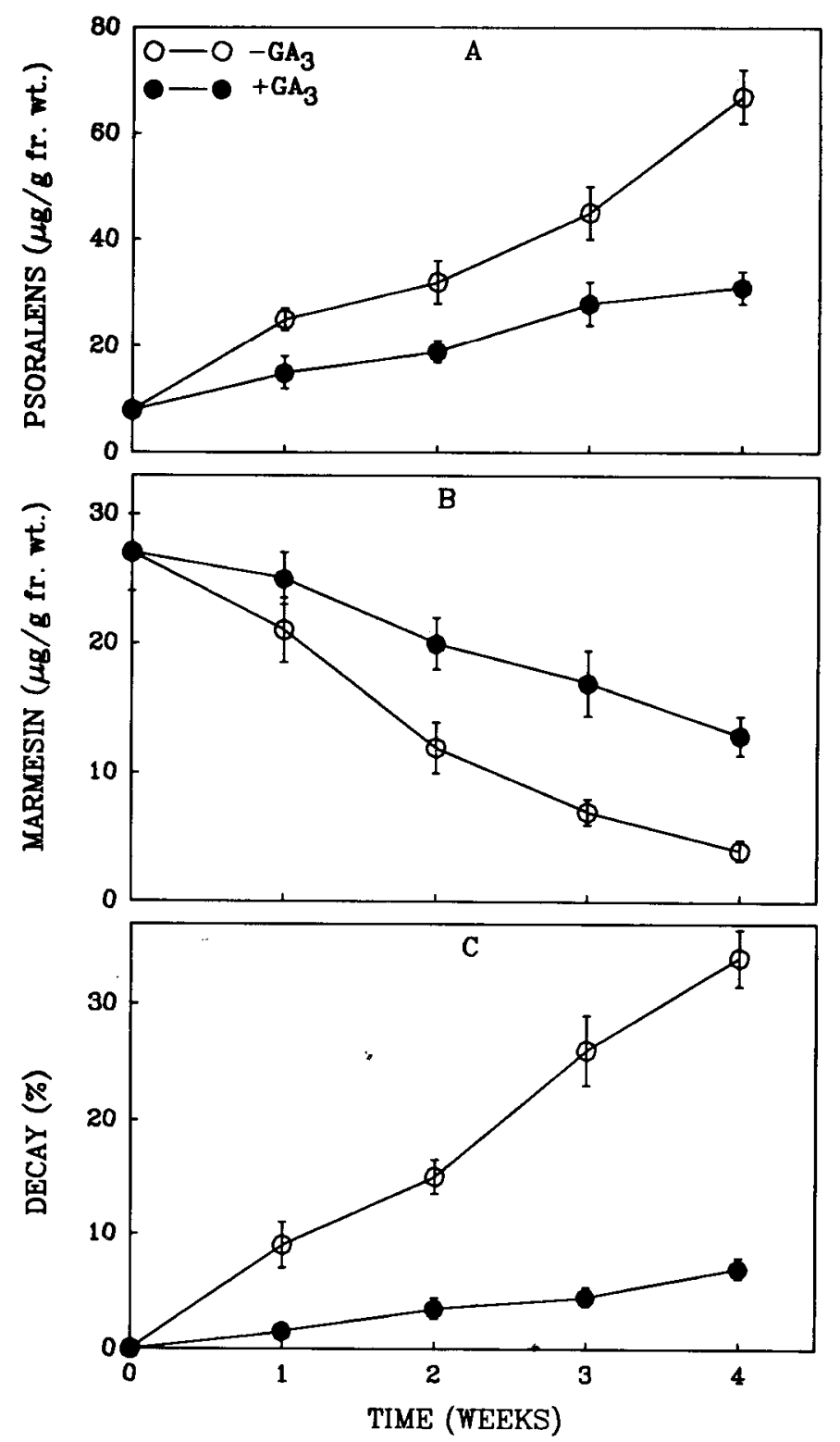

Fig. 1. Concentration of total psoralens (A) and (+)marmesin (B), and incidence of decay $(C)$ in celery during 4 weeks of storage at $2 \mathrm{C}$, treated and nontreated with $\mathrm{GA}_{3}$. Vertical bars indicate standard error. (+)marmesin is the major compound involved. In support of our findings, two other research groups recently reported that psoralens may not play a major role in disease and insect resistance of celery (Diawara et al., 1992, 1993; Heath-Pagliuso et al., 1992).

The conversion of (+)marmesin to the respective linear furanocoumarins involves the oxidative cleavage of the isopropyl alcohol sidechain and the introduction of a double bond to the fivemember ring moiety (Brown, 1978; Hamerski and Matem, 1988; Matem et al., 1988). We consider, therefore, that following this reaction the resultant products (psoralens), derived from (+)marmesin, lose about $99 \%$ of their antifungal activity.

Several studies (Aharoni and Richmond, 1978; Aharoni et al., 1975; Barkai-Golan and Aharoni, 198 1; Nooden, 1988; Shaul et al., 1992) reported that treatment with the phytohormone $\mathrm{GA}_{3}$ decreased plant decay caused by pathogens, but the mechanism of $\mathrm{GA}_{3}$ action in increasing plant resistance remained unclear. Similarly, the results of the present study show that celery stored after treatment with $\mathrm{GA}_{3}$ was more resistance to pathogens than the nontreated control.

Treatment of celery with $\mathrm{GA}_{3}$ before storage for 1 month at $2 \mathrm{C}$ resulted in $7 \%$ decay only. Concentrations of total psoralens and (+)marmesin after 1 month of storage at $2 \mathrm{C}$ following treatment with $\mathrm{GA}_{3}$ were 31 and $13 \mu \mathrm{g} \cdot \mathrm{g}^{-1}$ fresh weight, respectively (Fig. 1). $\mathrm{GA}_{3}$ does not have any effect on the growth of fungi and bacteria in vitro.

We suspect, therefore, that $\mathrm{GA}_{3}$ retarded celery decay during storage, by slowing down the conversion of $(+)$ marmesin to psoralens, thereby maintaining a high level of (+)marmesin and low levels of psoralens and, by this, increased celery resistance to pathogens during storage. This, in turn, may suggest a possible mechanism by which $\mathrm{GA}_{3}$ reduces celery decay during storage.

A routine postharvest treatment of celery with $\mathrm{GA}_{3}$ would achieve a double goal: decreasing psoralen concentration and contributing to consumer health and increasing the disease resistance in celery as an alternative to the postharvest application of pesticides, the use of which is limited in many countries.

\section{Literature Cited}

Aharoni, N. and A.E. Richmond. 1978. Endogenous gibberellin and abscisic acid content as related to senescence of detached lettuce leaves. Plant Physiol. 62:224-228.

Aharoni, N., A. Back, S. Ben-Yehoshua, and A.E. Richmond. 1975. Exogenous gibberellic acid and the cytokinin isopentenyladenine retardants of senescence in Romaine lettuce. J. Amer. Soc. Hort. Sci. 100:46.

Ashwood-Smith, M. J., A.T. Natarajan, and G.A. Poulton. 1982. Comparative photobiology of psoralens. J. Natl. Cancer Inst. 69: 189-197.

Ashwood-Smith, M. J., G.A. Poulton, M. Barker, and M. Mildenberger. 1980. 5-Methoxypsoralen, an ingredient in several suntan preparation, has lethal, mutagenic and clastogenic properties. Nature 285:407409. Austad, J. and G. Kalvi. 1983. Phototoxic dermatitis caused by celery infected by Sclerotinia sclerotiorum. Contact Dermatitis 9:448-451.

Barkai-Golan, R. and N. Aharoni. 1981. Combined disinfectant and growth substance treatment to delay deterioration in stored celery. Hassadeh 61:1484-1485 (Hebrew with English abstract).

Beier, R.C. 1985. A reverse phase technique for separating the linear furanocoumarins in celery. Liquid Chromatography 8: 1923-1932.

Beier, R.C. and E.H. Oertli. 1983. Psoralen and other linear furanocoumarins as phytoalexins in celery. Photochemistry 22:2595-2597.

Beier, R. C., G.W. Ivie, and E.H. Oertli. 1983a. Psoralens as phytoalexins in food plants of the fairly Umbelliferae, p. 295-3 10. In: J. Finaly and D. Schwass (eds.). Xenobiotics in foods and feeds. ACS Symp. Ser. 234, Amer. Chem. Soc., Washington, D.C.

Beier, R. C., G.W. Ivie, E.H. Oertli, and D.L. Holt. 1983b. HPLC analysis of linear furanocoumarins (psoralens) in healthy celery (Apium 
graveolens). Food Chem. Toxicol. 21:163-165.

Berkley, S. F., A.W. Hightower, R.C. Beier, D.W. Fleming, C.D. Brokopp, G.W. Ivie, and C.V. Broome. 1986. Dermatitis in grocery workers associated with high natural concentrations of furanocoumarins in celery. Ann. Internal Medicine 105:351-355.

Birmingham, D. J., M.K. Key, and G.E. Tubich. 1961. Phototoxic bullae among celery harvesters. Arch. Dermatol. 83: 128-141.

Brown. S.A. 1978. Biochemistry of the coumarins, p. 249-285. In:T. Swain, J.B. Harborne, and C.H. Van Sumere (eds.). Recent advances in photochemistry. Plenum Press, New York.

Bruyneel-Rapp, F., S.B. Dorsey, and J.D. Guin. 1988. The tanning salon: an area survey of equipment, procedures and practices. J. Amer. Acad. Dermatol. 18:1030-1038.

Chaudhary, S. K., O. Ceska, P.J. Warrington, and M.J. Ashwood-Smith 1985. Increased furanocoumarin content of celery during storage. J. Agr. Food Chem. 33:1153-1157.

Chin, T.U. and L. Beevers. 1970. Changes in endogenous growth regulators in Nasturtium leaves during senescence. Planta 92:178-188.

Dercks, W., J.T. Trumble, and C. Winter. 1990. Impact of atmospheric pollution on linear furanocoumarin content in celery. J. Chem. Ecol. 16:443-454.

Diawara, M. M., J.T. Trumble, and C.F. Quiros. 1993. Linear furanocoumarins of three celery breeding lines: Implications for integrated pest management. J. Agr. Food. Chem. 41:819-824.

Diawara, M. M., J.T. Trumble, C.F. Quiros, and J.G. Millar. 1992. Resistance to Spodoptera exigua (Lepidoptera: Noctuidae) in Apium prostratum. Entomol. Expt. Applications 64:125-133.

Finkelstein, A., U. Afek, E. Gross, N. Aharoni, L. Rosenberg, and S. Halevy. 1994. An outbreak of phytophotodermatitis due to celery. Intl. J. Dermatol. 33:116-118.

Floss, H.G. 1972. Biosynthesis of furanocoumarins, p. 143-164. In: V.C. Runeckles and J.A. Watkin (eds.). Recent advances in photochemistry. Appelton-CenturyCrofts, New York.

Floss, H.G. and U. Mothes. 1966. On the biosynthesis of furanocoumarins in Pimpinella manga. Phytochernistry 5:161-163.

Floss, H.G. and H. Paikert. 1969. Biosynthesis of furanocoumarins in Pimpinella manga (Umbelliferae). Photochemistry 8:589-593.

Hamerski, D. and U. Matem. 1988. Elicitor-induced biosynthesis of psoralens in Ammi majus L. suspension cultures. Microsomal conversion of demethylsuberosin into (+)marmesin and psoralen. Eur. J.
Biochem. 171:369-375.

Heath-Pagliuso, S., S.A. Maltin, N. Fang, R.H. Thompson, and L. Rappaport. 1992. Stimulation of furanocoumarin accumulation in celery and celeriac tissue by Fusarium oxysporum f. sp. apii. Phytochemisty 31:2683-2688.

IARC. 1983. Monograph on the evaluation of the carcinogenic risk of chemical to humans. Suppl. 4: Chemicals, industrial processes and industries associated with cancer in humans. IARC, Lyon, France.

Igali, S., B.A. Bridges, M.J. Ashwood-Smith, and B.R. Scott. 1970. IV. Photosensitization to near ultraviolet light by 8-methoxypsoralen. Mutation Res. 9:21-30.

Matem, U., H. Strasser, H. Wendorff, and D. Hamerski. 1988. Coumarins and furanocoumarins, p. 3-21. In: F. Constabel and I. Vasil (eds.). Cell culture and somatic cell genetics plants. Academic Press, New York.

Miller, R.D., S. Prakash, and L. Prakash. 1984. Different effects of RAD genes of Saccharomyces cerevisiae on incisions of interstrand crosslinks and monoadducts in DNA induced by psoralen plus near UV (ultra violet) light treatment. Photochem. Photobiol. 39:349-352.

Nooden, L.D. 1988. Abscisic acid, auxin, and other growth regulators of senescence, p. 330-355. In: L.D. Nooden and A.C. Leopold (eds.). Senescence and aging in plants. Academic Press, New York.

Pathak, M. A., F. Daniels, and T.B. Fitzpatrick. 1961. The presently known distribution of furanocoumarins (psoralens) in plants. J. Invest. Dermatol. 39:225-239.

Scott, B. R., M.A. Pathak, and G.R: Mohn. 1976. Molecular and genetic basis of furanocoumarins reactions. Mutation Res. 39:29-74.

Seligman, P.J., C.G. Mathias, M.A. O'Malley, R.C. Beier, L.J. Fehrs, W.S. Serril, and W.E. Halperin. 1987. Photodermatitis from celery among grocery store workers. Arch. Dermatol. 123: 1478-1482.

Shaul, O., Y. Elad, B. Kirshner, H. Volpin, and N. Zieslin. 1992. Control of Botrytis cinerea in cut rose flowers by gibberellic acid, ethylene inhibitors and calcium, p. 257-261. In: K. Verhoeff, N.E. Malatbrakis, and B. Williamson (eds.). Recent advances in Botrytis research. Pudoc Scientific Publishers, Wageningen, The Netherland.

Steck, W., M. Dakhakhny, and S.A. Brown. 1969. The role of marmesin and columbianetin in the biosynthesis of furanocoumarins. Tetrahedron Lett. 54:4805-4808.

Trumble, J. T., W. Dercks, C.F. Quiros, and R.C. Beier. 1990. Host plant resistance and linear furanocoumarins content of Apium accessions. J. Econ. Entomol. 83:519-525. 